\title{
TOTAL MIKROBIA JAMU SERBUK KEMASAN DAN TANPA KEMASAN PRODUK BANJARMASIN
}

\author{
Total Microbes of Herbs Packaging and Without Packaging \\ Product Banjarmasin \\ Ratih Indah Sari ${ }^{1}$, Sri Sinto Dewi ${ }^{2}$, Wildiani Wilson ${ }^{3}$ \\ ${ }^{1}$ Program Studi Ilmu Forensik Fakultas Sekolah Pascasarjana Universitas Airlangga. \\ ${ }^{2,3}$ Laboratorium Mikrobiologi Fakultas Ilmu Keperawatan dan Kesehatan \\ Universitas Muhammadiyah Semarang.
}

Korespondensi : ratihindahsari95@gmail.com/081250139171

\begin{abstract}
Traditional powder herbs is a heritage from Indonesia used for medication. Requirements of traditional powder herbs are secure, useful and to keep quality so that it doesn't contain microbial. This study aim is to know the total of microbial on a packaging and without packaging herbs production of Banjarmasin. This type of research is Observational Analytical research with a research draft using the Cross Sectional approach method. Samples in this study are packaging and without packaging herbs production of Banjarmasin. Counting total of microbial uses Total Plate Count method. The average total microbial of packing herb sample is $58.90 \%$, while the average total microbial of packaging herb sample is $65.20 \%$. Data were analyzed using the Mann Withney test and the result is 0,462 with p-value<0,05 so there is no significant correlation between packaging herb total microbial.
\end{abstract}

Keywords:Microbes, Non Packaging, Packaging herbs

\begin{abstract}
ABSTRAK
Jamu serbuk tradisional merupakan suatu warisan turun temurun dari bangsa Indonesia yang digunakan untuk pengobatan. Syarat jamu serbuk tradisional yaitu aman, bermanfaat dan menjaga mutu agar tidak mengandung mikrobia. Penelitian ini bertujuan untuk mengetahui total mikrobia jamu serbuk kemasan dan tanpa kemasan produksi Banjarmasin. Jenis penelitian ini adalah penelitian Analitik Observasional dengan rancangan penelitian menggunakan metode pendekatan Cross Sectional. Sampel penelitian jamu serbuk kemasan, dan tanpa kemasan. Perhitungan total mikrobia menggunakan metode Total Plate Count. Nilai rata-rata pada total mikrobia jamu serbuk kemasan sebesar 58,90\%, sedangkan rata-rata total mikrobia pada jamu serbuk tanpa kemasan sebesar 65,20\%. Data dianalisis menggunakan uji Mann Withney diperoleh 0,462 dengan nilai $\mathrm{p}$ value $<0,05$ yaitu tidak menunjukan hubungan yang bermakna antara total mikrobia jamu kemasan dan tanpa kemasan.
\end{abstract}

Kata kunci : Jamu Serbuk Kemasan, Jamu Serbuk Tanpa Kemasan, Mikrobia 


\section{PENDAHULUAN}

Gaya hidup yang kembali ke alam (Back to nature) menyadarkan masyarakat pentingnya penggunaan bahan alami. Animo masyarakat semakin meningkat terhadap penggunaan obat tradisional serta perkembangan industri herbal medicine, dan health food di Indonesia semakin meningkat. Jamu merupakan salah satu ramuan obat tradisional yang memiliki komposisi bahan baku berupa jenis tumbuhan yang mempunyai khasiat obat, bahan hewan, dan bahan mineral sediaan cairan dari bahan (galenik) yang secara turun temurun digunakan untuk pengobatan (Kementerian RI 2012).

Bahan baku obat herbal dapat digunakan dalam bentuk segar, kering atau simplisia. Simplisia adalah bahan alami yang belum mengalami pengolahan apapun, sehingga dapat dimanfaatkan untuk pembuatan jamu serbuk, jamu gendong, atau jamu ramuan pribadi yang dikonsumsi dengan direbus atau diseduh (Sains and Rukmi 2009).

Pengendalian kualitas obat herbal untuk mencegah perkembangan bakteri dan jamur kontaminan pada proses pembuatan jamu serbuk, proses pemanenan bahan baku, transportasi (pengangkutan), penyimpanan, produksi, dan pendistribusian dapat menyebabkan tanaman obat menjadi subjek kontaminasi yang mengakibatkan pembusukan dan produksi mikotoksin (Qaher A. Mandeel 2005). Produksi mikotoksin khususnya alfatoksin harus menjadi perhatian utama dalam pembuatan obat herbal, pada alfatoksin total tidak lebih dari $20 \mu \mathrm{g} / \mathrm{kg}$ (Badan Pengawas Obat Dan Makanan Republik Indonesia 2014).

Kalimantan Selatan adalah daerah yang sebagian besar masih melakukan penjualan jamu serbuk hasil olahan sendiri. Jamu dibuat secara sederhana dan hanya menggunakan matahari sewaktu pengeringan. Jamu yang dijual dalam bentuk serbuk yang disimpan dalam toples, bertahan hingga beberapa minggu.

Pengujian rutin yang di lakukan oleh Balai Besar POM Banjarmasin pada tahun 2018 dalam rangka pemeriksaan sarana produksi dan distribusi obat tradisional, menemukan masih banyak terdapat industri-industri rumahan yang tidak memenuhi ketentuan hygiene dan sanitasinya karena tidak menerapkan Cara Pembuatan Obat Tradisional yang Baik (CPOTB) (Balai Besar POM Banjarmasin 2018).

Perkembangan bakteri dan jamur yang tidak terkontrol pada proses pembuatan jamu serbuk akan menyebabkan kontaminasi, dalam pengujian mikrobiologi pada uji bakteri dengan Angka Lempeng Total (ALT) yang mana menurut BPOM No 12 Tahun 2014 sesuai pasal 6 ayat 2 Peraturan Menteri Kesehatan tentang Persyaratan Obat Tradisional bahwa, jamu serbuk simplisia yang diseduh dengan air panas tidak boleh mengandung Angka Lempeng Total melebihi $10^{6} \mathrm{koloni} / \mathrm{g}$. Sedangkan pada uji jamur dengan Angka Kapang Khamir (AKK) yang mana jamu serbuk simplisia yang diseduh dengan air panas tidak boleh mengandung Angka Kapang Khamir melebihi $\leq 10^{4}$ koloni/g dan Kadar air $\leq 10 \%$ (Badan Pengawas Obat Dan Makanan Republik Indonesia 2014).

Faktor-faktor yang menjadi penyebab kontaminasi mikroba seperti kelembaban tinggi dapat memicu tingginya angka cemaran jamur. Kontaminasi bakteri dan jamur menyebabkan terjadinya penurunan berat, berkurangnya mutu jamu, menghasilkan alfatoksin yang bersifat toksik, karsinogenik dan mutagen sehingga dapat menimbulkan efek 
seperti menghilangkan nafsu makan, menurunkan kekebalan tubuh dan memicu kanker (Sari 2015). Jamu serbuk yang baik merupakan jamu yang bebas dari mikroba alfatoksin dan zat pewarna. Pengendalian kualitas dapat mencegah perkembangan bakteri dan jamur kontaminan pada proses pembuatan jamu serbuk. Penggunaan jamu tradisional sering mendapat keluhan karena tingginya tingkat kontaminasi bakteri dan jamur (BPOM 2011).

Pengendalian proses pembuatan dengan menerapkan Cara Pembuatan Obat Tradisional yang Baik (CPOTB) dan distribusi obat tradisional (Direktorat Pengawasan Obat Tradisional Dan Suplemen Kesehatan 2018). Proses produksi dan penanganan bahan baku dapat menjamin produk yang dihasilkan telah memenuhi syarat yang sesuai dengan khasiat, keamanaan dan mutu (BPOM 2011).

Kurangnya tingkat hygiene dalam pembuatan dan penyimpanan jamu serbuk dapat menyebabkan tingginya kontaminasi bakteri dan jamur maka tujuan penelitian yaitu mengetahui total mikrobia pada jamu serbuk kemasan, jamu serbuk tanpa kemasan, serta menganalisis perbedaan total mikrobia pada jamu serbuk kemasan, dan jamu serbuk tanpa kemasan.

\section{METODE}

\section{Desain, tempat dan waktu}

Analitik Observasional dengan pendekatan Cross sectional, variabel bebas dalam penelitian ini adalah jamu serbuk kemasan dan tanpa kemasan sedangkan variabel terikat dalam penelitian ini adalah total mikrobia.

Populasi yang diambil dalam penelitian ini terdiri dari 4 pedagang jamu serbuk sirih industri rumah tangga, setiap pedagang memiliki 2 toples maka jumlah sampel 8 toples yang diambil keseluruhan sedangkan pada jamu serbuk sirih kemasan kertas disesuaikan dengan komposisi dan sampel berjumlah 8 kemasan. Untuk menghindari terjadinya sekecil mungkin kesalahan maka dilakukan replikasi atau pengulangan pada sampel sebanyak 3 kali pengulangan. Analisis data dalam penelitian ini menggunakan multivariat, dengan tujuan dapat menganalisis beberapa variabel terhadap variabel lain dalam waktu bersamaan, sehingga dapat menjelaskan atau mendiskripsikan karakteristik dari variabel yang diteliti. Dalam variabel yang diteliti terdapat variabel independen yaitu jamu serbuk kemasan dan jamu serbuk tanpa kemasan merupakan jamu industri rumah tangga produksi Banjarmasin, sedangkan variabel dependen mengukur total mikrobia dengan menganalisis perbedaan pada jamu serbuk sirih kemasan dan tanpa kemasan.

Metode penghitungan pada pertumbuhan bakteri dan jamur yaitu dengan metode Total Plate Count menggunakan teknik Spread Plate. Tempat penelitian dilaksanakan di Laboratorium Mikrobiologi dan Laboratorium Kimia Universitas Muhammadiyah Semarang (UNIMUS) jalan Kedungmundu Raya No.18 Semarang. Waktu penelitian dilakukan pada Agustus 2017.

\section{Bahan dan alat}

Alat yang digunakan pada sampel ini adalah tabung reaksi (pyrex), erlenmeyer (pyrex), petri disk, inkubator, mikroskop, autoclave, oven, laminar air flow, neraca analitik.

Bahan dan reagen yang digunakan pada sampel ini adalah jamu serbuk sirih tradisional industri rumah tangga (tanpa kemasan), jamu serbuk sirih kemasan kertas, $\mathrm{NaCl}$ fisiologis, Plate Count Agar (PCA) (OXOID). 


\section{Langkah-Langkah Penelitian}

A. Sterilasi/ Tindak Proses Steril Alat

Alat yang terbuat dari gelas sebelum digunakan dicuci terlebih dahulu sampai bersih, dikeringkan kemudian dibungkus dengan kertas, diautoclave pada suhu $121^{\circ} \mathrm{C}$ dengan tekanan 2 atm selama 15 menit setelah itu dikeringkan dalam oven suhu $150^{\circ} \mathrm{C}$ selama 3 menit.

\section{B. Pengenceran Sampel}

Metode Pengenceran sampel dilakukan dengan mencampurkan $1 \mathrm{gr}$ jamu serbuk ditambahkan dengan $9 \mathrm{ml}$ $\mathrm{NaCl}$ fisiologis. Larutan ini merupakan pengenceran $10^{-1}$, selanjutnya sebanyak $1 \mathrm{ml}$ diambil dari pengenceran $10^{-1}$ dan dilakukan pengenceran secara bertingkat sehingga diperoleh pengenceran $10^{-2}, 10^{-}$ ${ }^{3}, 10^{-4}, 10^{-5}, 10^{-6}, 10^{-7}, 10^{-8}, 10^{-9}$ sampai $10^{-10}$ Hitung Jumlah Bakteri

Pertumbuhan bakteri menggunakan media Plate Count Agar(PCA). Ambil sebanyak 0,1 ml dari pengenceran $10^{-8}, 10^{-9}, 10^{-10}$ ditanam pada media dengan teknik spread plate selanjutnya diinkubasi dengan suhu 35$37^{\circ} \mathrm{C}$ dalam waktu 1-2 hari lihat dan hitung koloni yang tumbuh pada media dengan metode Total Plate Count.

C. Hitung Jumlah Jamur

Pertumbuhan jamur merupakan lanjutan dari pemeriksaan bakteri yang mana pada hasil media yang telah di tumbuhi koloni kemudian diinkubasi dalam suhu $20-25^{\circ} \mathrm{C}$ dengan prosedur pemeriksaan angka lempeng total, larutan ini merupakan pengenceran $10^{-1}$ dan dilakukan pengenceran sampai $10^{-10}$. Sebanyak $0,1 \mathrm{ml}$ diambil dari pengenceran $10^{-8}, 10^{-9}, 10^{-10}$ ditanam pada media dengan teknik spread plate selanjutnya diinkubasi dengan suhu 20$25^{\circ} \mathrm{C}$ dalam waktu 5-7 hari lihat dan hitung koloni yang tumbuh pada media dengan metode Total Plate Count.

D. Pengukuran Kadar Air
Sampel jamu serbuk ditimbang sebanyak 1 gram dan dimasukkan ke dalam cawan porselin yang telah diketahui beratnya, kemudian dikeringkan dalam oven dengan suhu $100-105^{\circ} \mathrm{C}$ selama 2 jam dilakukan pemanasan berulang-ulang kali atau sampai beratnya konstan. Selisih berat sebelum dan sesudah pengeringan merupakan kadar air dalam bahan.

$$
\text { Kadar Air }=\frac{\text { Berat awal }- \text { berat akhir }}{\text { berat awal }} \times 100 \%
$$

\section{Pengolahan dan Analisis Data}

Data primer yang diambil dari hasil pengamatan dilakukan pencatatan dalam bentuk tabulasi data, kemudian dilakukan uji statistik dan dihitung menggunakan program komputer, adapun uji analisa data total mikrobia sampel kemasan dihubungkan dengan sampel tanpa kemasan yaitu diuji normalitas menggunakan uji Shapiro Wilk dilanjutkan dengan uji Mann Whitney

Analisis data yang digunakan dalam penelitian ini adalah multivariat. Data yang diperoleh dari penelitian ini diuji normalitasnya menggunakan uji Shapiro Wilk dan dilanjutkan dengan uji Mann Whitney.

\section{HASIL}

Subjek penelitian diambil secara purposive sampling dengan menentukan kriteria inklusi dalam pengambilan sampel pada sampel jamu serbuk tanpa kemasan yang merupakan produksi rumah tangga serta letak penyimpanan jamu tersebut hanya pada toples kaca, sedangkan pada jamu serbuk kemasan terdiri dari jamu serbuk kemasan yang memiliki kemasan yang tidak kedap udara, dan kemasan yang tidak tertutup rapat.

Pemeriksaan pada jamu serbuk dilakukan penghitungan jumlah bakteri dan jamur pada jamu serbuk sirih 
industri rumah tangga tanpa kemasan dan kemasan menunjukkan nilai ratarata pada total mikrobia jamu serbuk kemasan sebesar $58.90 \%$, sedangkan rata-rata total mikrobia pada jamu serbuk tanpa kemasan sebesar $65.20 \%$. Hasil pengukuran total mikrobia pada sampel kemasan dan tanpa kemasan dilakukan uji normalitas dengan uji Shapiro Wilk menunjukkan hasil analisis p-value 0,00 bahwa semua data total mikrobia pada jamu serbuk kemasan dan tanpa kemasan tidak berdistribusi normal apabila hasil analisis $\geq 0,05$ maka uji non parametrik yang digunakan yaitu uji Mann Whitney. Hasil uji statistik Mann Whithney total mikrobia jamu serbuk kemasan dan total mikrobia tanpa kemasan menunjukkan hasil analisis $p$ value 0,462 tidak terdapat perbedaan yang signifikan apabila hasil analisis $(\mathrm{p} \leq 0,05)$.

\section{PEMBAHASAN}

Total mikrobia sediaan jamu serbuk dalam penelitian ini ditentukan berdasakan hasil nilai Angka Lempeng Total dan Angka Kapang Khamir koloni bakteri dan jamur dirujukkan pada ketentuan batas cemaran maksimal yang telah ditetapkan oleh BPOM dan KEMENKES. Pengujian mikrobia ALT dan AKK pada sampel jamu serbuk sirih industri rumah tangga dalam berbagai pengenceran pada media pertumbuhan yaitu media Plate Count Agar (PCA).

Hasil penelitian menunjukkan meskipun secara statistik tidak bermakna, namun terlihat bahwa nilai rata-rata pada total mikrobia jamu serbuk kemasan sebesar 58,90\%. Sedangkan rata-rata total mikrobia pada jamu serbuk tanpa kemasan sebesar 65,20\%.

Diperkuat dari hasil rata-rata kadar air pada sampel tanpa kemasan yaitu $27,12 \%$ lebih tinggi dari pada sampel yang kemasan yaitu sebesar 24,87\%. Menurut Sains and Rukmi, (2009) hal ini disebabkan kadar air yang terlalu tinggi akan mengakibatkan banyaknya kontaminan bahan, serta lingkungan penyimpanan atau kemasan yang kurang memenuhi persyaratan.

Dilihat dari hasil angka lempeng total bakteri tanpa kemasan menunjukkan lebih banyak ditumbuhi bakteri dibandingkan pada jamu serbuk kemasan. Berdasarkan acuan perkembangan, bakteri pada suhu optimum $\quad 35-37^{\circ} \mathrm{C}$ memiliki kecenderungan tingkat cemaran bakteri yang tinggi dan dapat dengan mudah mencemari alat serta bahan pangan yang menyebabkan gangguan saluran pencernaan (Prahastiwi 2014).

Pada angka kapang khamir menunjukkan hasil yang sama dimana lebih banyak koloni jamur pada sampel tanpa kemasan, dengan suhu optimum pertumbuhan jamur adalah $20-35^{\circ} \mathrm{C}$ sehingga memungkinkan untuk tumbuhnya spora pada obat tradisional yang sensitive terhadap mikrobiologis.

Beberapa faktor yang mengakibatkan terjadinya kontaminasi mikroba antara lain seperti kelembaban tinggi yang dapat memicu tingginya angka cemaran jamur dan faktor jamu yang lembab sehingga menyebabkan pertumbuhan mikroba cukup banyak (Sains and Rukmi, 2009).

Pada hasil penelitian ini tidak terdapat pertumbuhan Aspergillus sp pada jamu serbuk tradisional berbeda dengan penelitian sebelumnya yang dilakukan oleh Rismawati, (2014) di Banjarmasin Tengah dimana terdapat 20 sampel cemaran Aspergillus sp yang sangat tinggi terbagi atas 16 sampel (80\%) positif Aspergillus sp dan 4 sampel negatif (20\%) Aspergillus sp. Hal ini dikarenakan perbedaan kandungan kadar air pada setiap simplisia pada penelitian ini lebih rendah sehingga kemudian menghambat tumbuhnya spesies-spesies tertentu. 
Uji angka lempeng total digunakan untuk menghitung banyaknya bakteri yang tumbuh dan berkembang pada sampel, sebagai acuan yang dapat menentukan kualitas dan keamanan simplisia. Apabila serbuk tercemar dan terus-menerus pengkonsumsian dapat menghasilkan toksin yang menyebabkan berbagai penyakit diantaranya diare, muntah, demam, dan infeksi yang timbul pada pencernaan karena infeksi bakteri Escherichia coli pada dinding usus menimbulkan gerakan larutan dalam jumlah besar dan merusak kesetimbangan elektrolit dalam membran mukosa. Hal ini dapat mengakibatkan penyerapan air pada dinding usus berkurang dan mengakibatkan diare. Pada masa inkubasi bakteri Escherichia coli adalah 6-24 jam hingga akhirnya gejala semakin parah pada tubuh orang yang terjangkit (M Radji 2010).

Pada obat tradisional yang berupa serbuk diseduh dengan air panas tidak boleh Angka Kapang Khamir tidak melebihi dari $10^{4} \mathrm{koloni} / \mathrm{g}$, mikroba patogen negatif dan alfatoksin total tidak lebih dari $20 \mu \mathrm{g} / \mathrm{kg}$ (BPOM 2014). Apabila dikonsumsi, maka aflatoksin dalam jumlah tinggi dapat menyebabkan terjadinya aflatoksikosis akut yang dapat menimbulkan manifestasi hepatoksisitas atau kasus berat dapat menyebabkan kematian. Bila aflaktosikosis ini berkelanjutan maka akan muncul sindrom penyakit yang ditandai dengan muntah, diare, nyeri perut, kejang, koma, dan kematian akibat edema otak serta perlemakan hati, ginjal dan jantung Maka dari itu alfatoksin juga disebut sebagai racun kedua dan karsinogen (Sari 2015).

Kapang khamir dan bakteri memerlukan Aw(water activity) yang paling tinggi untuk pertumbuhannya, bakteri dapat hidup pada water activity 0,86 , bakteri bersifat halofilik atau dapat tumbuh pada kadar garam tinggi dapat hidup pada nilai water activity lebih rendah yaitu 0,75 . Kandungan air dalam bahan obat tradisional mempengaruhi daya tahan bahan terhadap serangan mikroba yang dinyatakan Aw yaitu jumlah air bebas yang dapat digunakan mikroorganisme untuk pertumbuhannya. Berbagai mikroorganisme mempunyai Aw minimum agar tumbuh dengan baik, misalnya bakteri Aw : 0,90 ;kapang Aw : 0,60-0,70 ; khamir Aw : 0,80-0,90.

Tingginya nilai kadar air pada sampel tanpa kemasan dapat memberikan peluang hidup dan berkembang biaknya segala jenis mikrobia sehingga dapat menyebabkan terjadinya peningkatan kadar air dan kelembaban udara (Sains and Rukmi 2009). Syarat bahan yang memenuhi standar keamanan dan mutu antara lain pada, proses pembuatan dengan menerapkan CPOTB, memenuhi persyaratan Farmakope Herbal Indonesia, dapat berkhasiat dan dapat dibuktikan secara turun temurun. Cara Pembuatan Obat Tradisional yang Baik (CPOTB) agar lebih memperhatikan pada proses produksi dan penangan bahan baku agar dapat menjamin produk yang dihasilkan telah memenuhi syarat yang sesuai dengan mutu dan tujuan penggunaannya (BPOM 2011).

Menurut KEPMENKES No. 661/IMENKES/SK/VII/1994 tentang persyaratan obat tradisional bahwa angka kapang dan khamir tidak boleh lebih dari $10^{4} \mathrm{koloni} / \mathrm{g}$ dan agar tidak ditumbuhi cendawan, maka kadar air pada sampel kemasan dan tanpa kemasan tidak lebih dari $10 \%$. Berdasarkan Badan Pengawas Obat Dan Makanan No. 12 Tahun 2014 Tentang Persyaratan Mutu Obat Tradisional bahwa angka lempeng total tidak boleh melebihi $10^{6}$ koloni/g dan angka kapang khamir $10^{4} \mathrm{koloni} / \mathrm{g}$. 


\section{KESIMPULAN}

Berdasarkan hasil penelitian jamu serbuk tanpa kemasan industri rumah tangga memiliki hasil cemaran yang lebih tinggi dibandingkan pada hasil cemaran jamu serbuk kemasan. Bahwa tingginya tingkat pengenceran maka hasil kontaminasi pada jamu serbuk juga tinggi. Syarat mutu obat tradisional adalah angka lempeng total tidak boleh melebihi $10^{6} \mathrm{koloni} / \mathrm{g}$ dan angka kapang khamir $10^{4} \mathrm{koloni} / \mathrm{g}$.

\section{SARAN}

Beberapa saran pada penelitian ini antara lain:

1. Bagi produsen diharapkan agar lebih menerapkan Cara Pembuatan Obat Tradisional yang Baik (CPOTB) dan memperhatikan penyimpanan jamu, di khususkan pada produsen rumahan untuk mendaftarkan usaha jamunya kepada dinas kesehatan setempat.

2. Bagi BPOM agar mengambil tindakan preventif aktif yakni memberikan edukasi berupa bahaya dalam CPOTB yang menyalahi aturan.

3. Bagi konsumen diharapkan untuk lebih aktif dalam mencari tau kandungan dari jamu yang akan dikonsumsi serta mencari tau brand produsen jamu yang terpercaya.

\section{UCAPAN TERIMA KASIH}

Penulis ingin menyampaikan ucapan terima kasih kepada ibu Sri Sinto Dewi dan ibu Wildiani Wilson atas segala bimbingan, dukungan, dan bantuan yang telah diberikan kepada penulis sehingga berbagai kendala yang dihadapi dalam penulisan ini dapat teratasi.

\section{DAFTAR PUSTAKA}

Badan Pengawas Obat Dan Makanan Republik Indonesia. 2014. "Persyaratan Mutu Obat Dalam
Serbuk Simplisia Yang Diseduh Dengan Air Panas Sebelum Digunakan." Pp. 11-12 in Persyaratan Mutu Obat Tradisional. Jakarta.

Balai Besar POM Banjarmasin. 2018. Pengawasan Mutu, Keamanan Dan Kemanfaatan Obat Tradisional. Banjarmasin.

BPOM. 2011. "Badan Pengawas Obat Dan Makanan Republik Indonesia. "Pp. 4-6 in Persyaratan Teknis Cara Pembuatan Obat Tradisional Yang Baik. Jakarta.

BPOM. 2014. "Peraturan Kepala BPOM

Tebtang Persaratan Mutu Obat Tradisional." Bpom Ri.

Direktorat Pengawasan Obat Tradisional dan Suplemen Kesehatan. 2018. Pengawasan Sarana Obat Tradisional Dan Suplemen Kesehatan. Jakarta.

Kementerian RI. 2012. "Kementerian Kesehatan Republik Indonesia." Pp. 3-5 in Registrasi Obat Tradisional. Jakarta.

M Radji. 2010. Buku Ajar Mikrobiologi Panduan Mahasiswa Farmasi Dan Kedokteran.

Prahastiwi, R. .. 2014. "Efek Ekstrak Daun Sirih Merah Terhadap Pertumbuhan Bakteri Bacillus Cereus ATTC 14745 Dan Shigella Flexneri ATCC 12022 Serta Mekanisme Penghambatannya." Fakultas Sains Dan Teknologi UIN Sunan Kalijaga.

Qaher A. Mandeel. 2005. "Fungal Contamination of Some Imported Spices." Fungal Contamination of Some Imported Spices 159(Issue 2):291-298.

Rismawati Irliani. 2014. "Cemaran Aspergillus Sp Pada Jamu Serbuk Tradisional Yang Di Jual Di Banjarmasin Tengah." Fakultas Analis Kesehatan Stikes Borneo Lestari. 
Sains, Jurnal and Isworo Rukmi. 2009. "Keanekaragaman Tradisional." 17(April):82-89.

Sari, Ratih Indah. 2015. "Cemaran Aspergillus Sp Pada Jamu Serbuk Kemasan Yang Dijual Di Banjarbaru Selatan." Fakultas Analis Kesehatan Stikes Borneo Lestari. 


\section{Lampiran Hasil}

Tabel 1 Nilai rata-rata Total Mikrobia pada Jamu Serbuk Kemasan danTanpa Kemasan

\begin{tabular}{|c|c|c|c|c|c|c|}
\hline \multirow[t]{2}{*}{ Sampel } & \multicolumn{3}{|c|}{ Kemasan (CFU/ml) } & \multicolumn{3}{|c|}{$\begin{array}{r}\text { Tanpa Kemasan } \\
(\mathrm{CFU} / \mathrm{ml})\end{array}$} \\
\hline & $\begin{array}{l}\text { Jumlah } \\
\text { bakteri }\end{array}$ & $\begin{array}{c}\text { Jumlah } \\
\text { jamur }\end{array}$ & $\begin{array}{c}\text { Total } \\
\text { Mikrobia }\end{array}$ & $\begin{array}{l}\text { Jumlah } \\
\text { bakteri }\end{array}$ & $\begin{array}{c}\text { Jumlah } \\
\text { jamur }\end{array}$ & $\begin{array}{c}\text { Total } \\
\text { mikrobia }\end{array}$ \\
\hline 1 & 8 & 0 & 8 & 11.45 & 1.5 & 12.95 \\
\hline 2 & 15.15 & 1 & 16.15 & 380 & 0 & 380 \\
\hline 3 & 52 & 0 & 52 & 16.5 & 0 & 16.5 \\
\hline 4 & 1.1 & 1 & 2.1 & 4.15 & 3 & 7.15 \\
\hline 5 & 13.8 & 0 & 13.8 & 19.5 & 4.9 & 24.4 \\
\hline 6 & 33 & 0 & 33 & 40 & 0 & 40 \\
\hline 7 & 1.2 & 0 & 1.2 & 15.2 & 2 & 17.2 \\
\hline 8 & 345 & 0 & 345 & 21.5 & 2 & 23.5 \\
\hline $\begin{array}{l}\text { Rata- } \\
\text { rata }\end{array}$ & & & 58.90 & & & 65.20 \\
\hline
\end{tabular}

Sumber Data Penelitian, 2017
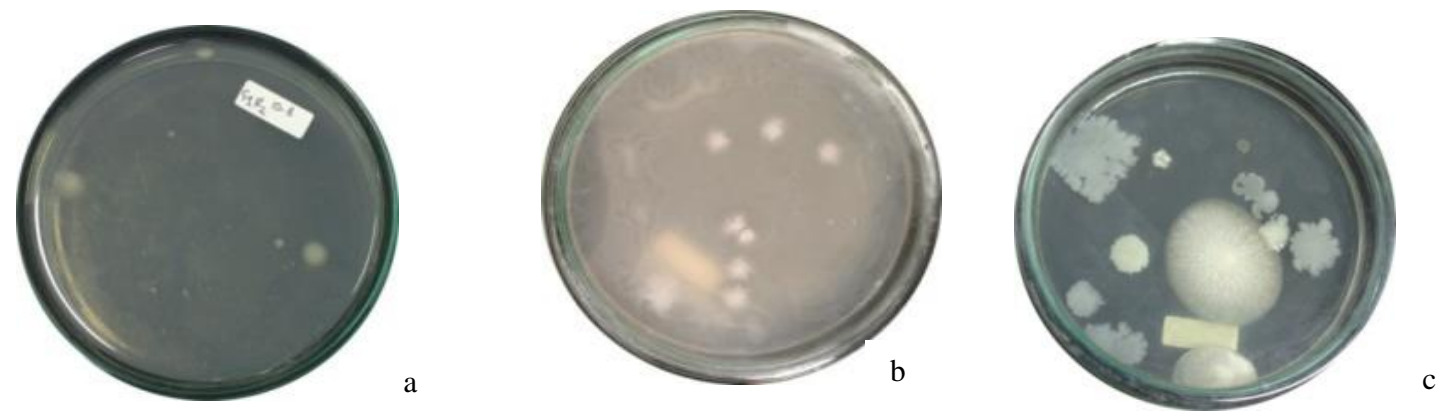

Gambar 1. Hasil Pengamatan Pertumbuhan Mikrobia Jamu Serbuk Tanpa Kemasan. a. Hasil inkubasi 24 jam b. Hasil inkubasi 72 jam c. Hasil inkubasi 7 hari
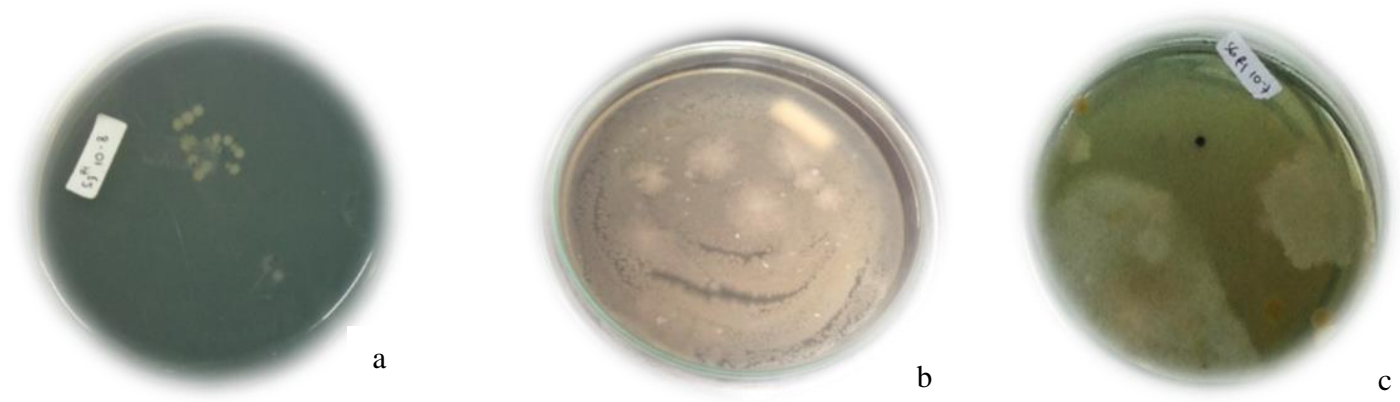

Gambar 2. Hasil Pengataman Pertumbuhan Mikrobia Jamu Serbuk Kemasan.

a. Hasil inkubasi 24 jam b. Hasil Inkubasi 72 jam c. Hasil inkubasi 7 hari. 
Tabel 2. Uji Normalitas Shapiro Wilk pada total mikrobia jamu serbuk kemasan dan tanpa kemasan

\begin{tabular}{lcc}
\multicolumn{1}{c}{ Variabel } & Statistik & P value \\
\hline $\begin{array}{l}\text { Total Mikrobia Sampel } \\
\text { Kemasan }\end{array}$ & 545 & 0,00 \\
\hline $\begin{array}{l}\text { Total Mikrobia Sampel } \\
\text { Tanpa Kemasan }\end{array}$ & 488 & 0,00 \\
Sumber Data Penelitian, 2017 & &
\end{tabular}

Sumber Data Penelitian, 2017

Tabel 3. Hasil uji statistik Mann Whithney total mikrobia jamu serbuk kemasan dan tanpa kemasan

\begin{tabular}{lcc}
\hline \multicolumn{1}{c}{ Variabel } & $p$ value & Keterangan \\
\hline Total mikrobia kemasan & 0,462 & Tidak ada perbedaan \\
Total mikrobia tanpa kemasan & 0,462 & Tidak ada perbedaan \\
\hline
\end{tabular}

Sumber Data Penelititan, 2017

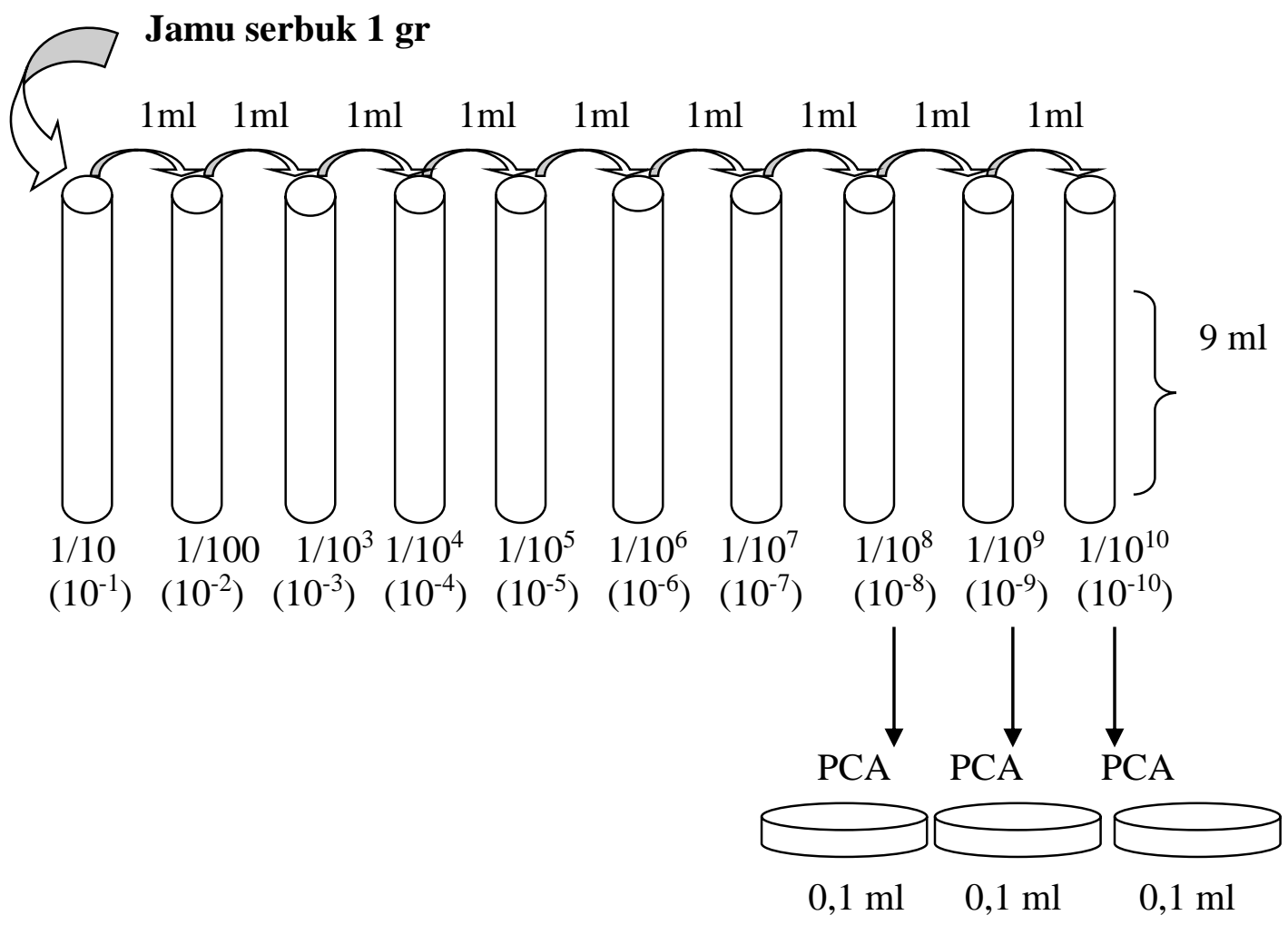

Gambar 3. Prosedur plate count atau hitung cawan dengan menggunakan seri pengenceran. 